\title{
Performance and Reliability of SiC Power MOSFETs
}

Daniel J. Lichtenwalner, ${ }^{1}$ Brett Hull, ${ }^{1}$ Vipindas Pala, ${ }^{1}$ Edward Van Brunt, ${ }^{1}$ Sei-Hyung Ryu, ${ }^{1}$ Joe J. Sumakeris, ${ }^{2}$ Michael J. O'Loughlin, ${ }^{1}$ Albert A. Burk, ${ }^{1}$ Scott T. Allen, ${ }^{1}$ and John W. Palmour ${ }^{1}$

${ }^{1}$ Wolfspeed, a Cree Company, 3028 E. Cornwallis Rd, Research Triangle Park, NC 27709, U.S.A.

${ }^{2}$ Cree, Inc. 4600 Silicon Drive, Durham, NC 27703, U.S.A.

\begin{abstract}
Due to the wide bandgap and other key materials properties of $4 \mathrm{H}-\mathrm{SiC}, \mathrm{SiC}$ MOSFETs offer performance advantages over competing Si-based power devices. For example, $\mathrm{SiC}$ can more easily be used to fabricate MOSFETs with very high voltage ratings, and with lower switching losses. Silicon carbide power MOSFET development has progressed rapidly since the market release of Cree's $1200 \mathrm{~V} 4 \mathrm{H}-\mathrm{SiC}$ power MOSFET in 2011. This is due to continued advancements in $\mathrm{SiC}$ substrate quality, epitaxial growth capabilities, and device processing. For example, high-quality epitaxial growth of thick, low-doped $\mathrm{SiC}$ has enabled the fabrication of SiC MOSFETs capable of blocking extremely high voltages (up to $15 \mathrm{kV}$ ); while dopant control for thin highly-doped epitaxial layers has helped enable low on-resistance 900V SiC MOSFET production. Device design and processing improvements have resulted in lower MOSFET specific on-resistance for each successive device generation. SiC MOSFETs have been shown to have a long device lifetime, based on the results of accelerated lifetime testing, such as hightemperature reverse-bias (HTRB) stress and time-dependent dielectric breakdown (TDDB).
\end{abstract}

\section{INTRODUCTION}

Wide bandgap semiconductors have a clear advantage for power device operation, due primarily to the wider bandgap resulting in lower intrinsic carrier concentrations, and low impact ionization rates (or higher critical fields before avalanche breakdown) $[1,2]$. The favored polytype for power devices is $4 \mathrm{H}-\mathrm{SiC}$, as it has a wide bandgap $(3.26 \mathrm{eV})$, and high electron mobility $\left(\sim 1000 \mathrm{~cm}^{2} \mathrm{~V}^{-1} \mathrm{~s}^{-1}\right)$ both parallel to and perpendicular to the c-axis direction [3].

However, due to the many structural polytypes formed by SiC, many years of development were required to achieve single-polytype substrates with low defect densities and good doping control, which then enabled high quality epitaxial layers [4]. Presently, highquality substrates of $150 \mathrm{~mm}$ diameter are available from various suppliers, and Cree recently demonstrated the capability of producing $200 \mathrm{~mm}$ diameter $4 \mathrm{H}-\mathrm{SiC}$ substrates, with uniform epitaxial growth capability on $200 \mathrm{~mm}$ wafers as well [5]. Preserving the polytype control during epitaxial growth is typically accomplished using an off-axis substrate orientation ( $4^{\circ}$ off-axis in the $\{11-20\}$ direction) such that step-flow growth dominates [6].

The development of quality power MOSFET devices has been dependent on the $4 \mathrm{H}-\mathrm{SiC}$ crystal quality. As the dominant $\mathrm{SiC}$ MOSFET structure is a vertical device, with current flow and electrical field vertical from top-to-bottom (Fig. 1), defects in the epitaxial drift layer have a major impact on device performance. The major SiC crystalline defects which have traditionally hampered power device performance have been micro-pipes (MPs), and basal-plane dislocations (BPDs). These have resulted in either high leakage currents causing failure under high bias (MPs), or resistance drift during bipolar operation (BPDs). Presently, MP densities have been 
reduced to $<0.5 \mathrm{~cm}^{-2}$, and BPD densities are similarly low in the device drift region due to careful control of the epitaxial growth conditions as described previously [4].

Aided by these material advances, in 2011 Cree announced the $1^{\text {st }}$ commercial SiC MOSFET, a $1200 \mathrm{~V}$ rated device [7]. Since then, additional product generations, as well as $1700 \mathrm{~V}$ and $900 \mathrm{~V}$ rated devices, have been released. Highlighting the good $4 \mathrm{H}-\mathrm{SiC}$ epitaxial quality, Cree has demonstrated MOSFET devices with up to $15 \mathrm{kV}$ rating as well [8]. In the following sections, issues related to $\mathrm{SiC}$ MOSFET device materials processing, device performance, and reliability will be summarized.

\section{SiC MATERIALS ISSUES}

\section{MOSFET SiC drift layer}

SiC power MOSFET design typically follows the traditional 'DMOSFET' structure [1] as shown in Fig. 1, in which the electric field is dropped vertically across the epitaxial $\mathrm{SiC}$ drift layer with bias applied at the drain (bottom), while the metal-oxide-semiconductor (MOS) electron channel is planar (horizontal). The planar channel is typically formed on the $\mathrm{SiC}(0001)$ face, termed the 'Si-face', as this face has resulted in good epitaxial growth control and forms a high quality oxide upon oxidation anneal. Other device variants, such as the trench MOSFET, will not be discussed in detail here. However, it is worth noting that for the trench structure, the MOS channel is on a different $\mathrm{SiC}$ face, which has implications for the MOS channel resistance and oxide quality.

Due to the superior materials properties of $\mathrm{SiC}$, the drift layer providing electric field blocking can be much thinner for $\mathrm{SiC}$ than for $\mathrm{Si}$, and the doping level can be higher, offering lower resistance [1]. A figure-of-merit (FOM) for the semiconductor drift layer in the 1-D parallel-plane case is expressed as

$$
\frac{V_{B}^{2}}{R_{\text {on }, s p}}=\left(\mu_{N} \epsilon_{S} E_{C}^{3}\right) / 4
$$

where $V_{B}$ is the maximum blocking voltage, $R_{o n, s p}$ is the specific on-resistance $\left(\mathrm{ohm}-\mathrm{cm}^{2}\right), \mu_{N}$ is the electron mobility $\left(\mathrm{cm}^{2} \mathrm{~V}^{-1} \mathrm{~s}^{-1}\right), \epsilon_{\mathrm{S}}$ is the semiconductor dielectric constant, and $\mathrm{E}_{\mathrm{C}}$ is the critical electric field strength. Due to the higher critical field strength of $\mathrm{SiC}$ compared to Si for a given drift doping level, the device blocking voltage can be much higher for $\mathrm{SiC}$ at a given $\mathrm{R}_{\text {on,sp. }}$. This is shown in Fig. 2, displaying the 1-D limits of a Si drift layer compared to a $4 \mathrm{H}-\mathrm{SiC}$ drift layer (this includes the dependence of $E_{C}$ and electron mobility $\left(\mu_{\mathrm{N}}\right)$ on doping). Also shown in Fig. 2 are the values obtained from fabricated Cree SiC MOSFET devices rated from $900 \mathrm{~V}$ to $15 \mathrm{kV}$. It is clear that for a given voltage rating, the $\mathrm{SiC}$ device has a much lower specific resistance. For Si devices, getting the same overall resistance thus requires a much larger die size. Though it has been shown that a Si power MOSFET with a 2-D or 3-D drift structure (such as a superjunction [9]) can result in lower a $R_{o n, s p}$ than the $S i$ 1-D limit, it is still well above the value achievable with the simpler 1-D drift structure in present $\mathrm{SiC}$ power MOSFETs. 


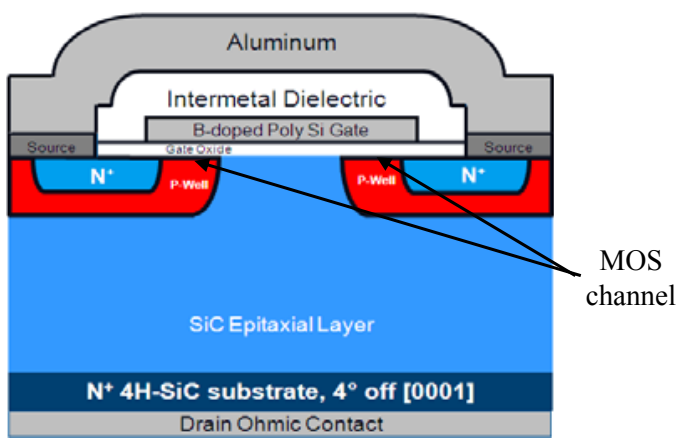

Fig. 1. Schematic cross-section of a SiC vertical DMOSFET structure. The MOS channel is planar, while the $\mathrm{SiC}$ epitaxial drift layer supports the vertical current (on-state) and electrical field (off-state).

\section{MOS channel interface}

Besides the drift resistance, the MOS channel resistance is another critical component of the total MOSFET on-state resistance. It is evident from the graph in Fig. 2 that the total device resistance rises above the drift limit for devices rated below about $3 \mathrm{kV}$. The channel resistance becomes a larger percentage of total device resistance as the drift layer is thinned, which is the case for lower-voltage-rated devices. From the $4 \mathrm{H}-\mathrm{SiC}$ bulk mobility, it would be expected that a channel inversion layer mobility of $\sim 200 \mathrm{~cm}^{2} \mathrm{~V}^{-1} \mathrm{~s}^{-1}$ should be attainable for moderately doped channels $\left(\sim 1 \times 10^{16} \mathrm{~cm}^{-3}\right)$. In the past, very high interface state density $\left(\mathrm{D}_{\mathrm{IT}}\right)$ near the $\mathrm{SiC} / \mathrm{SiO}_{2}$ interface resulted in extremely low channel (inversion layer) mobility in 4H-SiC MOSFETs, such that the benefits of the $\mathrm{SiC}$ materials properties were not fully realized. However, the demonstration of the effect of nitric oxide (NO) annealing on lowering $\mathrm{D}_{\mathrm{IT}}$ levels and thus raising the field-effect channel mobility $\left(\mu_{\mathrm{FE}}\right)$ from about $\sim 3$ to $30 \mathrm{~cm}^{2} \mathrm{~V}^{-1} \mathrm{~s}^{-1}[10]$ helped to make practical low-resistance MOSFET devices a reality. It has been determined that the $\mathrm{NO}\left(\right.$ or $\left.\mathrm{N}_{2} \mathrm{O}\right)$ post-oxidation anneals result in $\mathrm{N}$ accumulation at the interface, which lowers the $\mathrm{D}_{\text {IT }}$ level of shallow e- traps, and may also result in near-surface counterdoping of the SiC. Besides N passivation, it has also been shown that oxide anneals in $\mathrm{POCl}_{3}[11]$ result in high $\mu_{\mathrm{FE}}$ values. We have recently shown that Barium at the $\mathrm{SiC} / \mathrm{SiO}_{2} \mathrm{MOS}$ interface also results in high $\mu_{\mathrm{FE}}$ values [12], greater than $80 \mathrm{~cm}^{2} \mathrm{~V}^{-1} \mathrm{~s}^{-1}$. This is shown in Fig. 3, comparing the measured $\mu_{\mathrm{FE}}$ from lateral MOSFETs fabricated on p-type $\left(5 \times 10^{15} \mathrm{~cm}^{-3}\right) \mathrm{SiC}$ with a Ba interface layer compared to that of a NO treated sample. The Ba sample has double the mobility, which would result in half the channel resistance. A lower interface state density is believed to be the principal reason for this improvement, as shown by the measured $\mathrm{D}_{\text {IT }}$ obtained from high-low C$\mathrm{V}$ measurements on n-type capacitors (Fig. 4). Although this high-low method underestimates the total $\mathrm{D}_{\mathrm{IT}}$ in $\mathrm{SiC}$ devices [13] it has proven useful for comparing relative trap densities between samples. 


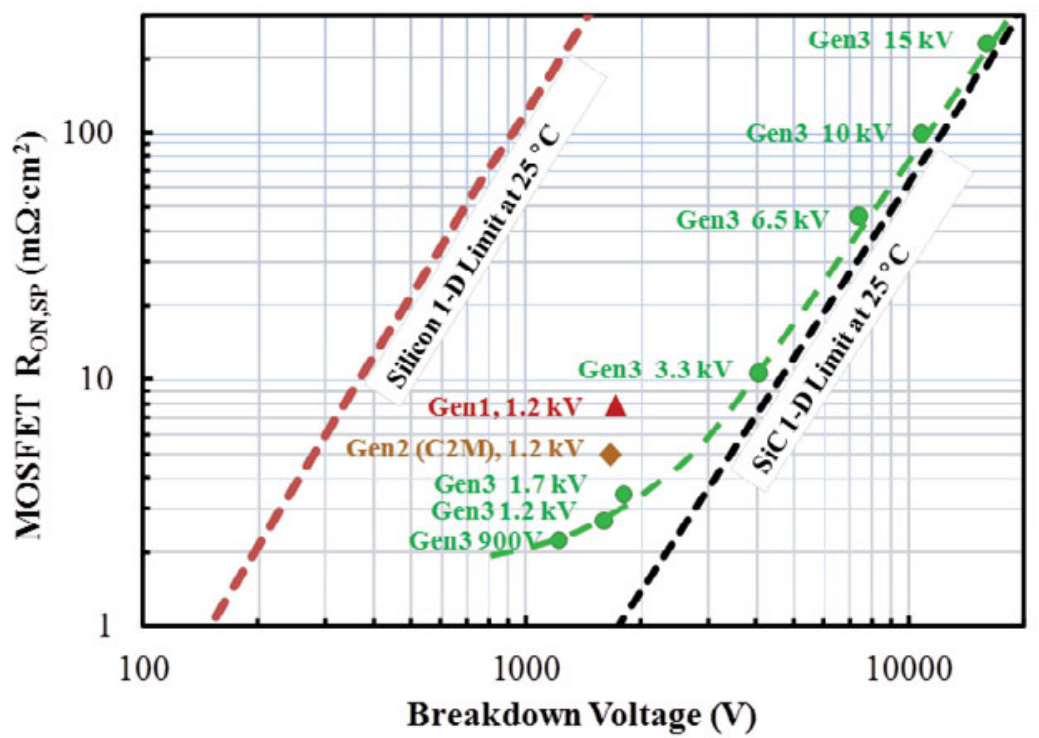

Fig. 2. Comparison of $\mathrm{Si}$ and $4 \mathrm{H}-\mathrm{SiC}$ drift layer properties, in terms of $\mathrm{R}_{\mathrm{on}, \mathrm{sp}}$ and breakdown voltage $\mathrm{V}_{\mathrm{B}}$. Included are points describing the performance points of Cree MOSFETs at room temperature, as reported by Palmour et al. [8].

It is also possible that other effects are present which raise the field-effect mobility, such as a high dielectric constant oxide near the interface (such as a thin barium silicate layer), or other effects which change the interface fields. For a comprehensive review of MOS-related issues in $\mathrm{SiC}$, see the recent publication of Liu et al [14].

\section{SiC MOSFET ELECTRICAL PERFORMANCE}

\section{Medium-voltage rated devices $(900 \mathrm{~V}$ to $1200 \mathrm{~V})$}

As there are a host of electrical power applications requiring devices with voltage ratings up to $\sim 1700 \mathrm{~V}[1,2]$, and Si power device resistance increases rapidly with voltage rating, this voltage range served as a logical entry point for low-resistance $\mathrm{SiC}$ power devices [7].

Some key MOSFET properties are the device voltage rating, on-resistance, and threshold voltage. Normally-off (enhancement mode) devices are typically preferred, requiring a threshold voltage of a few volts to ensure the device can block current flow without bias on the gate. The device resistance determines power losses in the on-state, while the overall device structure and semiconductor material determines switching losses.

Typical on-state properties are shown in Fig. 5 for a Cree 1200V, $80 \mathrm{mOhm}$ MOSFET (C2M0080120D) mounted in a TO-247 package. The device is rated to $150{ }^{\circ} \mathrm{C}$, and the on- 


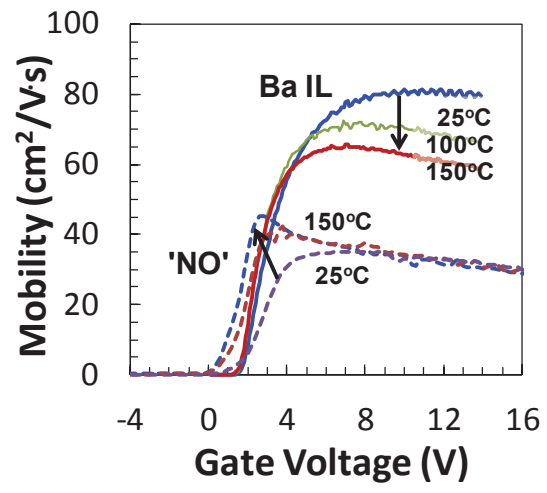

Fig. 3. Comparison of nitric oxide $(\mathrm{NO})$ and $\mathrm{Ba}$ interface layer $(\mathrm{Ba} \mathrm{IL})$ passivation effects on $4 \mathrm{H}-\mathrm{SiC}$ field-effect mobility.

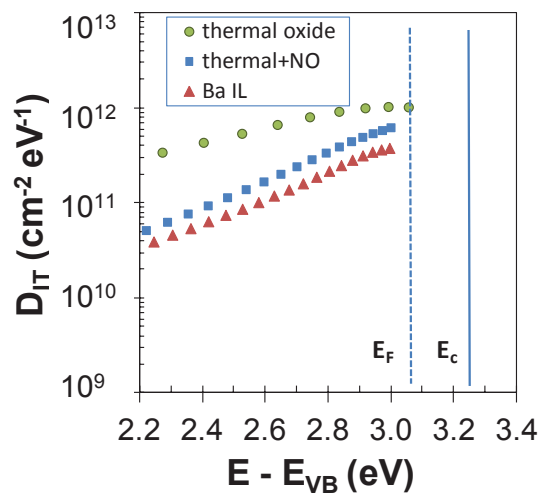

Fig. 4. Interface state density $\left(\mathrm{D}_{\mathrm{IT}}\right)$ of MOS capacitors, comparing an unpassivated thermal oxide on $\mathrm{SiC}$ to that of $\mathrm{N}(\mathrm{NO})$ or Ba passivated samples.

state gate bias specification is $20 \mathrm{~V}$. Device specifications ensure a threshold voltage of $>2.4 \mathrm{~V}$, and less than $100 \mathrm{uA}$ of leakage in the off-state with $1200 \mathrm{~V}$ of drain bias at $25^{\circ} \mathrm{C}$. As indicated in Fig. 6, as temperature is increased to $150^{\circ} \mathrm{C}$, the on-resistance increases 1.6 times. A slight increase in resistance with temperature helps prevent thermal runaway conditions.

An overall device operation range is compactly shown by the 'safe-operating-area' (SOA) plot in Fig.7. This clearly demonstrates the drain voltage $\left(\mathrm{V}_{\mathrm{DS}}\right)$ and current $\left(\mathrm{I}_{\mathrm{DS}}\right)$ limits of a given device. The drift region doping and thickness largely determines the maximum possible voltage; while the device on-resistance determines the $\mathrm{I}_{\mathrm{DS}}$ current limit as $\mathrm{V}_{\mathrm{DS}}$ increases from $0 \mathrm{~V}$ to about $10 \mathrm{~V}$. At higher $\mathrm{V}_{\mathrm{DS}}$, the maximum current allowed eventually decreases as thermal

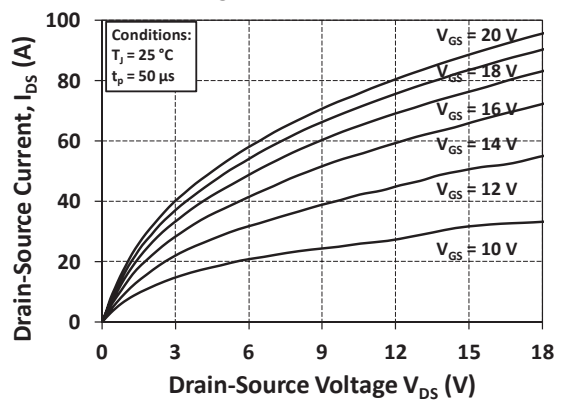

Fig. 5. Output characteristics of a Cree $1200 \mathrm{~V}$ $80 \mathrm{mOhm}$ MOSFET at $25^{\circ} \mathrm{C}$.

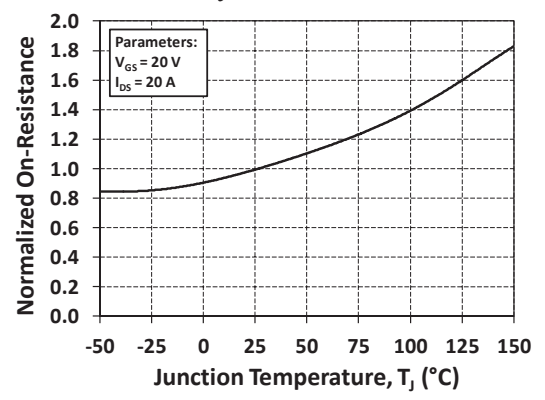

Fig. 6. Normalized on-resistance versus device temperature (1200V MOSFET). 


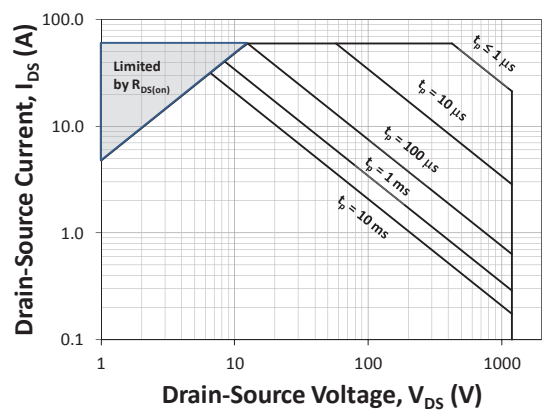

Fig. 7. Safe-operating-area graph for a Cree $1200 \mathrm{~V} 80 \mathrm{mOhm}$ MOSFET at $25^{\circ} \mathrm{C}$.

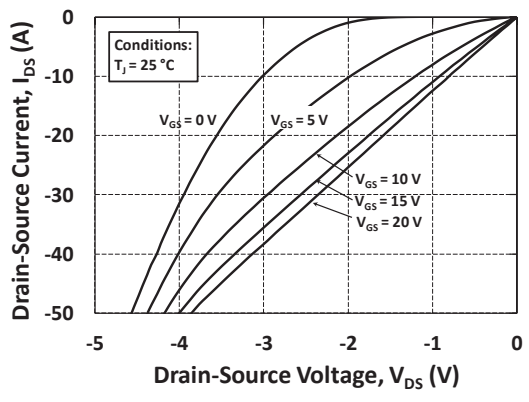

Fig. 8. 1200V MOSFET third-quadrant operation; a linear I-V with the channel on $\left(20 \mathrm{~V}_{\mathrm{G}}\right)$, and the PN body-diode current with the gate off $\left(\mathrm{V}_{\mathrm{G}}=0\right)$.

dissipation would result in heating above the rated temperature of $150{ }^{\circ} \mathrm{C}$. The current limit is higher for short current pulses, shown ranging from $10 \mathrm{~ms}$ to $1 \mu \mathrm{s}$.

What is not immediately obvious from the static performance is the fact that the low specific on-resistance offered by $\mathrm{SiC}$ (as in Fig. 2) allows a much smaller die size for a $\mathrm{SiC}$ device compared to a similarly rated Si device. This is an important factor resulting in a decrease of device capacitances (between gate, source, and drain) or more relevantly gate charges (e.g., gate to drain $\mathrm{Q}_{\mathrm{GD}}$; or total gate charge $\mathrm{Q}_{\mathrm{G}}($ tot)), which results in large reductions in switching losses for $\mathrm{SiC}$ devices. This results in lower thermal cooling requirements, and allows higher frequency switching, both of which lower system costs and energy costs.

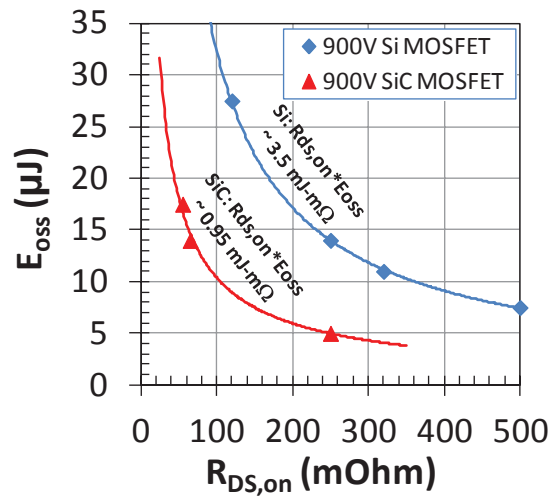

Fig. 9. A comparison of $\mathrm{SiC}$ and $\mathrm{Si}$ MOSFET efficiency, plotting the output stored energy $\left(\mathrm{E}_{\mathrm{oss}}\right)$ versus the on-resistance $\left(\mathrm{R}_{\mathrm{DS}, \text { on }}\right)$. A lower product indicates higher efficiency.

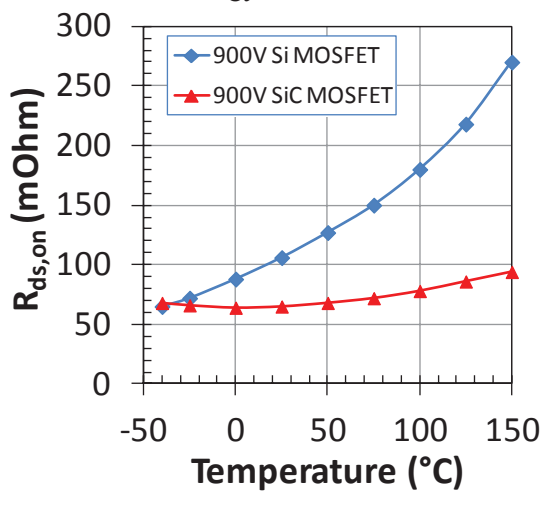

Fig. 10. A comparison of $\mathrm{SiC}$ and $\mathrm{Si}$ device resistance with temperature, up to $150^{\circ} \mathrm{C}$. The $\mathrm{SiC}$ device maintains a lower resistance, thus less conduction losses. 
An additional feature of a MOSFET is that under negative drain bias, current can flow through the channel if the device is on $\left(\mathrm{V}_{\mathrm{G}}=20 \mathrm{~V}\right)$, or through the body PN diode if the channel is off $\left(V_{\mathrm{G}}<\mathrm{V}_{\mathrm{T}}\right)$, shown in Fig. 8. This is important for a variety of applications; for example, a $\mathrm{SiC}$ MOSFET can provide the same function as an IGBT paired with an anti-parallel diode.

An example demonstrating the performance advantages of SiC MOSFETs is shown in Fig. 9, comparing Cree 900V SiC MOSFETs to Infineon 900V Si CoolMOS ${ }^{\circledR}$ MOSFETs. The output stored energy $\left(\mathrm{E}_{\mathrm{oss}}\right.$, derived from the drain to source capacitive charge) is proportional to switching power losses, while the on-resistance $\left(\mathrm{R}_{\mathrm{DS}, \text { on }}\right)$ is proportional to conduction power losses, so minimizing both parameters is key for device efficiency. It is clear that $\mathrm{SiC}$ MOSFETs, over a range of device on-resistance values, have much lower loss product $\left(\mathrm{R}_{\mathrm{DS}, \text { on }} * \mathrm{E}_{\mathrm{oss}}\right)$ indicating lower overall power losses are possible [15].

Another performance advantage is clear when comparing the $\mathrm{R}_{\mathrm{DS} \text {,on }}$ as a function of temperature. As evident in Fig. 10, for relatively closely rated devices, the SiC MOSFET maintains a significantly lower $\mathrm{R}_{\mathrm{DS} \text {, on }}$ to $150^{\circ} \mathrm{C}$, indicating much lower conduction losses. These performance advances have allowed $\mathrm{SiC}$ MOSFETs to be considered as the device of choice for a range of applications, including motor drives and solar invertors, among others.

\section{$\underline{\text { High-voltage rated devices (up to } 15 \mathrm{kV} \text { ) }}$}

The materials advances in $4 \mathrm{H}-\mathrm{SiC}$ epitaxial layer quality have been key to the fabrication of very high-voltage MOSFETs, from $3.3 \mathrm{kV}$ and higher. Because the drift layer is now the key resistive component (as evident in Fig. 2), and it must be very thick with very low doping to provide high blocking voltage, substrate and epitaxial layer quality now dominate the device performance. Using high quality $150 \mu \mathrm{m}$ thick $4.5 \times 10^{14} \mathrm{~cm}^{-3} \mathrm{~N}$-doped epitaxial layers, we have fabricated $15 \mathrm{kV}, 10 \mathrm{~A}$ rated $\mathrm{SiC}$ MOSFETs [16], demonstrating a specific on-resistance very close to the theoretical limit, as shown in Fig. 2. The output characteristics and blocking capability are shown in Figs. 11 and 12, respectively. The $\mathrm{R}_{\mathrm{on}, \mathrm{sp}}$ is just above $200 \mathrm{mOhm}-\mathrm{cm}^{2}$, while the devices block up to $16 \mathrm{kV}$ with $<1 \mu \mathrm{A}$ leakage. While similarly rated SiC IGBTs can have a lower on-state resistance, the MOSFET becomes favored at switching frequencies above about $5 \mathrm{kHz}$, due to inherently higher switching loss in bipolar devices [16]. This high of a voltage rating has yet to be demonstrated with silicon power semiconductor devices.

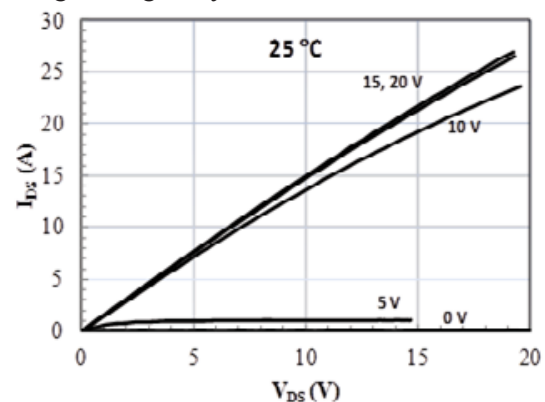

Fig. 11. On-state characteristics of a $15 \mathrm{kV}, 10 \mathrm{~A}$ rated $\mathrm{SiC}$ MOSFET at $25^{\circ} \mathrm{C}$.

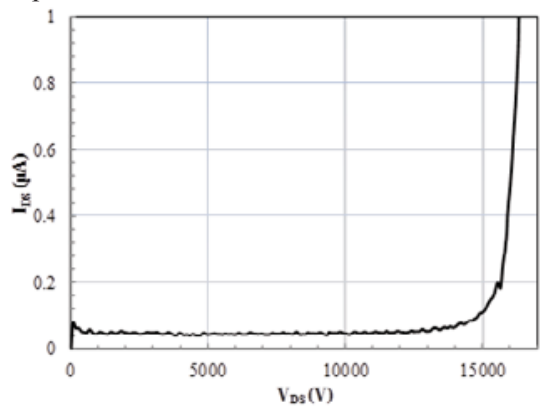

Fig. 12. Blocking capability of a $15 \mathrm{kV}, 10 \mathrm{~A}$ rated $\mathrm{SiC}$ MOSFET at $25^{\circ} \mathrm{C}$. 


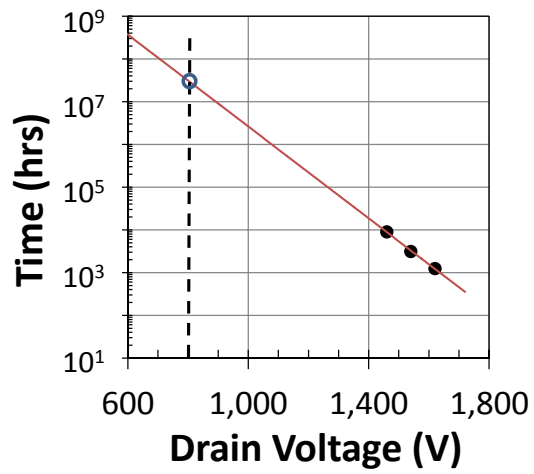

Fig. 13. Mean time to failure from accelerated HTRB testing of $1200 \mathrm{~V}$ SiC MOSFETs at high $\mathrm{V}_{\mathrm{DS}}$ stress, at $150^{\circ} \mathrm{C}$.

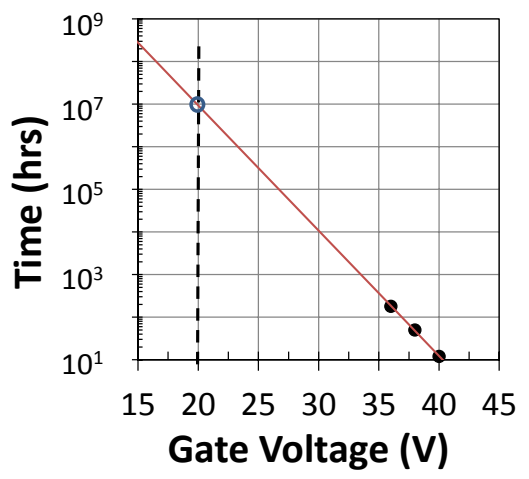

Fig. 14. Mean MOS gate failure time (TDDB) for $1200 \mathrm{~V} \mathrm{SiC} \mathrm{MOSFETs} \mathrm{stressed}$ at high $\mathrm{V}_{\mathrm{G}}$ values, at $150^{\circ} \mathrm{C}$.

\section{SiC MOSFET RELIABILITY}

Device performance must be linked with reliability for commercially viable devices. Key tests demonstrating expected device lifetime are: 1) high temperature reverse-bias (HTRB) stress; and 2) time-dependent dielectric-breakdown (TDDB) of the MOS gate dielectric. Both of these tests can be performed under accelerated conditions (above the device operation specifications), extrapolating to device operating conditions in order to obtain long-term failure probabilities, using appropriate mathematical functions.

Results of HTRB tests on $1200 \mathrm{~V} \mathrm{SiC} \mathrm{MOSFETs} \mathrm{stressed} \mathrm{at} 1460 \mathrm{~V}, 1540 \mathrm{~V}$, or $1620 \mathrm{~V}$ are shown in Fig. 1, showing the mean time to failure. The mean time to failure at an operating $\mathrm{V}_{\mathrm{DS}}$ of $800 \mathrm{~V}$ extrapolates to $3 \times 10^{7} \mathrm{hrs}$. TDDB test results at accelerated gate oxide fields are shown in Fig. 14. Extrapolating to the specified operational gate voltage of $20 \mathrm{~V}$, a mean time to failure of $1 \times 10^{7} \mathrm{hrs}$ is expected. Both tests indicate mean device lifetimes of $>1000$ yrs under normal device operating conditions. The commercial devices are subjected to a variety of other tests for qualification purposes, beyond the scope of the present report.

\section{CONCLUSIONS}

Due to many materials and processing advances, $4 \mathrm{H}-\mathrm{SiC}$ MOSFETs have become viable, high-performance power devices. Commercially available versions cover voltage ratings from $900 \mathrm{~V}$ to $1700 \mathrm{~V}$, and demonstration devices covering the range from $600 \mathrm{~V}$ up to $15 \mathrm{kV}$ have been fabricated and evaluated. Device reliability is rapidly improving, and devices in the $900 \mathrm{~V}$ to $1700 \mathrm{~V}$ ranges are being utilized for a host of power applications, due to the efficiency advantages which allow lower system costs and lower energy cost. 


\section{ACKNOWLEDGMENTS}

Portions of this work were sponsored by the Army Research Laboratory under Cooperative Agreement \#W911NF-12-2-0064, and \#W911NF-10-2-0038. The views and conclusions herein are those of the authors and should not be interpreted as representing the official policies, either expressed or implied, of the Army Research Laboratory or the U.S. Government. The U.S. Government is authorized to reproduce and distribute reprints for Government purposes notwithstanding any copyright notation herein.

\section{REFERENCES}

1. B.J. Baliga, Fundamentals of Power Semiconductor Devices, Springer Science, New York (2008).

2. T. Kimoto and J.A. Cooper, Fundamentals of Silicon Carbide Technology, IEEE Press, John Wiley \& Sons, Singapore (2014).

3. H. Iwata and K.M. Itoh, J. Appl. Phys. 89(11), 6228-6234 (2001).

4. J.J. Sumakeris, J.R. Jenny, and A.R. Powell, MRS Bulletin 30, 280-286 (2005).

5. A.R. Powell, J.J. Sumakeris, Y. Khlebnikov, M. Paisley, R. Leonard, M. O’Loughlin, E. Deyneka, S. Gangwal, J. Ambati, V. Tsvetkov, J. Seaman, A. McClure, C. Horton, O. Kramarenko, V. Sakhalkar, J. Guo, M. Dudley, and E. Balkas, Inter. Conf. on SiC and Related Materials (ICSCRM) (Oct. 5, 2015).

6. H.S. Kong, H.J. Kim, J.A. Edmond, J.W. Palmour, J. Ryu, C.H. Carter, Jr., J.T. Glass, and R.F. Davis, Mater. Res. Soc. Symp. Proc. 97, 233 (1987)

7. S. Davis, Power Electronics Technol., pp. 36-40, Feb. (2011).

8. J. W. Palmour, L. Cheng, V. Pala, E. V. Brunt, D. J. Lichtenwalner, G.-Y. Wang, J. Richmond, M. O'Loughlin, S. Ryu, S. T. Allen, A. A. Burk, and C. Scozzie, Proc. of the 26th Inter. Symp. on Power Semiconductor Devices \& IC's (ISPSD), pp. 79-82, (2014).

9. CoolMOS ${ }^{\mathrm{TM}}$ C7 Technology and Design Guide, Application Note AN 2013-04, V1.0 April (2013), Infineon Technologies.

10. G.Y. Chung, C.C. Tin, J.R. Williams, K. McDonald, R.K. Chanana, R.A. Weller, S.T. Pantelides, L.C. Feldman, O.W. Holland, M.K. Das, J.W. Palmour, IEEE Electron Dev. Lett. 22, 176-178 (2001).

11. D. Okamoto, H.Yano, K.Hirata, T.Hatayama, T.Fuyuki, IEEE Electron Dev. Lett. 31, 710712 (2010).

12. D.J. Lichtenwalner, L. Cheng, S. Dhar, A. Agarwal, J.W. Palmour, Appl. Phys. Lett. 105(18), 182107 (2014).

13. A. V. Penumatcha, S. Swandono, and J. A. Cooper, IEEE Trans. on Electron Devices 60(3), 923-926 (2013).

14. G. Liu, B.R. Tuttle, and S. Dhar, Appl. Phys. Rev. 2, 021307 (2015).

15. V. Pala, A. Barkley, B. Hull, G. Wang, S.-H. Ryu, E. Van Brunt, D.J. Lichtenwalner, J. Richmond, C. Jonas, D.C. Capell, S. Allen, J. Casady, D. Grider, J. Palmour, IEEE Energy Conversion Congress and Exposition (ECCE), pp. 4145-4150 (2015).

16. S.-H. Ryu, C. Capell, E. Van Brunt, C. Jonas, M. O’Loughlin, J. Clayton, K. Lam, V. Pala, B. Hull, Y. Lemma, D. Lichtenwalner, Q. J. Zhang, J. Richmond, P. Butler, D. Grider, J. Casady, S. Allen, J. Palmour, M. Hinojosa, C. W. Tipton and C. Scozzie, Semicond. Sci. Technol. 30, 084001 (2015). 